\section{OPEN ACCESS}

Edited by:

Masaaki Murakami,

Hokkaido University, Japan

Reviewed by:

Michael Dietrich,

University Hospital of

Düsseldorf, Germany

Naoto Kawakami,

Ludwig Maximilian University of

Munich, Germany

*Correspondence:

Hideyuki Takeuchi

htake@yokohama-cu.ac.jp

tThese authors have contributed equally to this work

Specialty section

This article was submitted to

Multiple Sclerosis and

Neuroimmunology,

a section of the journal

Frontiers in Immunology

Received: 10 October 2020

Accepted: 22 February 2021

Published: 11 March 2021

Citation:

Horiuchi H, Parajuli B, Komiya H,

Ogawa Y, Jin S, Takahashi K,

Azuma Y-T, Tanaka F, Suzumura A and

Takeuchi H (2021) Interleukin-19

Abrogates Experimental Autoimmune

Encephalomyelitis by Attenuating

Antigen-Presenting Cell Activation.

Front. Immunol. 12:615898

doi: 10.3389/fimmu.2021.615898

\title{
Interleukin-19 Abrogates Experimental Autoimmune Encephalomyelitis by Attenuating Antigen-Presenting Cell Activation
}

\begin{abstract}
Hiroshi Horiuchi ${ }^{1 \dagger}$, Bijay Parajuli ${ }^{1 \dagger}$, Hiroyasu Komiya ${ }^{2 \dagger}$, Yuki Ogawa ${ }^{2}$, Shijie Jin ${ }^{1}$, Keita Takahashi ${ }^{2}$, Yasu-Taka Azuma ${ }^{3}$, Fumiaki Tanaka ${ }^{2}$, Akio Suzumura ${ }^{1}$ and Hideyuki Takeuchi ${ }^{1,2 *}$
\end{abstract}

\footnotetext{
1 Department of Neuroimmunology, Research Institute of Environmental Medicine, Nagoya University, Nagoya, Japan, ${ }^{2}$ Department of Neurology and Stroke Medicine, Yokohama City University Graduate School of Medicine, Yokohama, Japan, ${ }^{3}$ Laboratory of Veterinary Pharmacology, Division of Veterinary Science, Osaka Prefecture University Graduate School of Life and Environmental Science, Izumisano, Japan
}

Interleukin-19 (IL-19) acts as a negative-feedback regulator to limit proinflammatory response of macrophages and microglia in autocrine/paracrine manners in various inflammatory diseases. Multiple sclerosis (MS) is a major neuroinflammatory disease in the central nervous system (CNS), but it remains uncertain how IL-19 contributes to MS pathogenesis. Here, we demonstrate that IL-19 deficiency aggravates experimental autoimmune encephalomyelitis (EAE), a mouse model of $M S$, by promoting IL-17-producing helper $\mathrm{T}$ cell (Th17 cell) infiltration into the CNS. In addition, IL-19-deficient splenic macrophages expressed elevated levels of major histocompatibility complex (MHC) class II, co-stimulatory molecules, and Th17 cell differentiation-associated cytokines such as IL-1 $\beta$, IL-6, IL-23, TGF- $\beta 1$, and TNF- $\alpha$. These observations indicated that $\mathrm{IL}-19$ plays a critical role in suppression of MS pathogenesis by inhibiting macrophage antigen presentation, Th17 cell expansion, and subsequent inflammatory responses. Furthermore, treatment with IL-19 significantly abrogated EAE. Our data suggest that IL-19 could provide significant therapeutic benefits in patients with MS.

Keywords: interleukin-19, macrophage, antigen presentation, experimental autoimmune encephalomyelitis, multiple sclerosis

\section{INTRODUCTION}

Multiple sclerosis (MS) and experimental autoimmune encephalomyelitis (EAE), a mouse model of MS, are major autoimmune demyelinating diseases of the central nervous system (CNS) $(1,2)$. Various types of immune cells and soluble mediators contribute to the complex mechanisms underlying the onset and progression of both MS and EAE, and recent studies have shown that type 1 helper $\mathrm{T}$ (Th1) cells and interleukin-17-producing helper $\mathrm{T}$ (Th17) cells play pivotal roles in their pathogenesis (3-5). In these diseases, autoreactive Th17 cells primed in the lymph nodes infiltrate the CNS and activate microglia/macrophages that induce inflammatory demyelination and subsequent neuronal damage, resulting in a wide range of clinical features, including sensory and motor paralysis, blindness, pain, incontinence, and dementia $(1,2)$. 
Interleukin-19 (IL-19) is an IL-10 family cytokine that is homologous and highly similar to IL-20 and IL-24 $(6,7)$. IL-19 binds to the heterodimeric receptor consisting of IL-20R $\alpha$ and IL-20R $\beta$, and its downstream signaling is mediated by STAT3 phosphorylation $(8,9)$. IL-19 is mainly produced by activated macrophages and microglia (10-13). Recent studies showed that IL-19 exerts antiinflammatory effects on macrophages by inhibiting inflammatory cytokine production, downregulating antigen-presenting capacity, and enhancing M2 phenotype polarization, which promotes type 2 helper $\mathrm{T}$ (Th2) cell differentiation and suppresses Th1 and Th17 cell differentiation (11, 12, 1417). In fact, IL-19 plays a critical role in development of various autoimmune diseases, including asthma (18, 19), psoriasis (20-22), inflammatory bowel disease (11, 23), rheumatoid arthritis (24), and Type I diabetes (25). However, it remains to be elucidated how IL-19 contributes to MS pathogenesis.

Here, we examined the pathological role of IL-19 in EAE using IL-19-deficient (IL-19-/-) mice. IL-19 deficiency markedly exacerbated EAE, and treatment with IL-19 effectively suppressed EAE accompanied by inhibiting macrophage antigen presentation and subsequent expansion of Th17 cells. Our findings suggest that IL-19 may provide significant therapeutic benefits for treating MS.

\section{MATERIALS AND METHODS}

\section{Reagents}

MOG peptide 35-55 $\quad$ MOG $_{35-55}$; MEVGWYRSPFSRVVHLYRNGK) was synthesized and purified by Operon Biotechnologies (Tokyo, Japan). Incomplete Freund's adjuvant was obtained from Sigma-Aldrich (St. Louis, MO, USA). Heat-killed Mycobacterium tuberculosis H37Ra was obtained from Difco (Detroit, MI, USA), and pertussis toxin was obtained from List Biological Laboratories (Campbell, CA, USA). Recombinant mouse IL-6, IL-19, and TGF- $\beta 1$ were obtained from R\&D Systems (Minneapolis, MN, USA).

\section{Animals}

All animal experiments were conducted under protocols approved by the Animal Experiment Committee of Nagoya University (approved numbers: 15017 and 15018) and Yokohama City University (approved number: F-A-19-036). C57BL/6J (B6) mice were purchased from Japan SLC (Hamamatsu, Japan). IL-19-/- mice (B6 background) $(11,12)$ were obtained from Regeneron Pharmaceuticals (Tarrytown, NY, USA).

\section{EAE Induction and Treatment Studies}

MOG-EAE was induced as previously described (26-28). In brief, 8-week-old female mice were immunized subcutaneously at the base of the tail with $0.2 \mathrm{ml}$ of emulsion containing $200 \mu \mathrm{g}$ $\mathrm{MOG}_{35-55}$ in saline, combined with an equal volume of complete Freund's adjuvant containing $300 \mu \mathrm{g}$ heat-killed Mycobacterium tuberculosis H37Ra. The mice were intraperitoneally injected with $200 \mathrm{ng}$ pertussis toxin on days 0 and 2 post-immunization. To investigate the effect of IL-19, EAE mice were treated with mouse recombinant IL-19 protein $(20 \mathrm{ng} / \mathrm{g}$ of body weight) by intraperitoneal injection every other day starting on day 2 post-immunization, according to a modification of a previously reported method $(29,30)$. The mice were assessed daily for clinical signs of EAE, according to the following grading system: 0, normal; 1, limp tail or mild hind limb weakness; 2 , moderate hind limb weakness or mild ataxia; 3, moderate to severe hind limb weakness; 4, severe hind limb weakness, mild forelimb weakness or moderate ataxia; 5, paraplegia with moderate forelimb weakness; and 6, paraplegia with severe forelimb weakness, severe ataxia, or moribundity.

\section{Isolation of Cells From Spleen and Lumbar Spinal Cord}

Mononuclear cells were collected from the spleen and lumbar spinal cord as described previously (26-28). $\mathrm{CD}^{+}, \mathrm{CD}^{+} 1 \mathrm{~b}^{+}$, and $\mathrm{CD}_{11 \mathrm{c}^{+}}$cells were isolated using the MACS system (Miltenyi Biotec, Bergisch Gladbach, Germany). Helper T cell differentiation was induced as described previously (5, 28, 31). For flow cytometric analysis, cells were stained with PerCP/Cy5.5 or BV421-conjugated anti-mouse CD4 rat monoclonal antibody (RM4-5; BD Biosciences, Franklin Lakes, NJ, USA). The cells were then fixed and permeabilized with Cytofix/Cytoperm reagent (BD Biosciences) and stained with $\mathrm{PE}$-conjugated anti-mouse IFN- $\gamma$ rat monoclonal antibody (XMG1.2; BD Biosciences) and APC- or PE-conjugated antimouse IL-17A rat monoclonal antibody (TC11-18H10; BD Biosciences). The samples were analyzed using a FACS Aria III system (BD Biosciences) and the FlowJo software (FlowJo, Ashland, OR, USA).

\section{Histological Analysis}

Histological analysis was performed as previously described $(26,27)$. Mice with peak EAE were anesthetized and perfused transcardially with $4 \%$ paraformaldehyde in $0.1 \mathrm{M}$ PBS. Lumbosacral spinal cords were immediately removed, post-fixed in $4 \%$ paraformaldehyde, and embedded in paraffin or OCT compound (Sakura Finetek Japan, Tokyo, Japan). Eight-micronthick paraffin sections were stained with hematoxylin and eosin. Stained sections were analyzed on a NanoZoomer 2.0-RS slide scanner (Hamamatsu Photonics, Hamamatsu, Japan). For immunofluorescence staining, the frozen sections $(20 \mu \mathrm{m})$ were permeabilized with $0.1 \%$ Triton X-100 in PBS for 20 min, blocked with $5 \%$ bovine serum for $30 \mathrm{~min}$, and then incubated overnight with rat anti-mouse F4/80 monoclonal antibody (CI:A3-1; 1:1,000, AbD Serotec, Raleigh, NC, USA), rabbit antimouse iNOS polyclonal antibodies (1:5,000, Merck Millipore), and goat anti-mouse Arginase-1 polyclonal antibodies (1:200, Proteintech) followed by incubation with Alexa Fluor 488 or $546-$ conjugated secondary antibodies (Life Technologies, Carlsbad, CA, USA). The stained cells were analyzed by examining six random fields per section using a deconvolution fluorescence microscope system (BZ-X800, Keyence, Osaka, Japan). The data were collected from three animals per group. 


\section{RNA Extraction and Reverse-Transcription Polymerase Chain Reactions (Rt-PCRs)}

We evaluated the expression levels of proinflammatory factors in the lumbar spinal cords and spleens by qPCR as described previously $(12,26)$. In brief, lumbar spinal cords and spleens were collected from EAE mice at pre-immunization, EAE onset, and EAE peak (approximately on days 0, 10, 16 postimmunization, respectively). Total RNA was isolated with an RNeasy Mini Kit (Qiagen, Valencia, CA, USA) and reverse transcribed with SuperScript III (Life Technologies, Carlsbad, CA, USA). Expression levels of mRNAs were evaluated by qPCR using SYBR Select Master Mix (Applied Biosystems, Foster City, CA, USA) on a Rotor-Gene Q (Qiagen) or LightCycler 96 (Roche). Mouse gene-specific primers were obtained from Life Technologies (Table 1). Gene-expression values were determined using the $\Delta \Delta \mathrm{C}_{\mathrm{T}}$ method. Levels of mRNAs of interest were standardized to the geometric mean of the level of hypoxanthine phosphoribosyltransferase 1 (Hprt1). Assays were carried out in three independent trials.

\section{Statistical Analysis}

Statistical significance was analyzed using Student's $t$-test, oneway analysis of variance (ANOVA), or repeated measures ANOVA followed by post-hoc Tukey's test in GraphPad Prism version 8 (GraphPad Software, La Jolla, CA, USA).

\section{RESULTS}

\section{IL-19 Deficiency Exacerbates EAE}

We generated myelin oligodendrocyte glycoprotein (MOG)induced EAE in C57BL/6J wild-type (WT) and IL-19-deficient $\left(\mathrm{IL}-19^{-/-}\right)$mice. We already confirmed that IL-19-/- mice without immunization showed no inflammatory cell infiltration in the CNS as well as WT mice (Supplementary Figure 1). IL$19^{-/-}$mice exhibited earlier disease onset and more severe symptoms than WT mice (Figure 1A). Histological analysis of the lumbar spinal cords revealed more inflammatory cell infiltration in IL-19-/- mice than in WT mice (Figure 1B). Quantitative analysis also disclosed that IL-19-/- EAE mice had more infiltrating cells in the lumbar spinal cords than WT EAE mice (Figure 1C). We then chronologically evaluated IL-19 expression levels in the spleen and lumbar spinal cord of WT mice at pre-immunization, disease onset, and disease peak. Splenic IL-19 mRNA expression was upregulated at disease onset, but was strongly suppressed at the disease peak (Figure 1D). By contrast, upregulation of IL-19 mRNA in the lumbar spinal cord was observed at disease peak (Figure 1E). These results suggest that endogenous IL-19 serves as a negative regulator of EAE pathogenesis at both the induction and effector phases.

\section{IL-19 Deficiency Increases Th17 Cell Infiltration Into the CNS}

Because EAE is a Th1 and Th17 cell-mediated autoimmune disease, we next assessed whether IL-19 deficiency would increase CNS infiltration of Th1 and Th17 cells. Flow cytometric analysis revealed that at disease peak, IL-19- $19^{-/}$mice exhibited
TABLE 1 | Primers for qPCR.

\begin{tabular}{|c|c|}
\hline Gene & Primer sequence \\
\hline mouse I/19 sense & CAACCTGCTGACATTCTACAGAG \\
\hline mouse //19 antisense & CCTGACATCGCTCCAGAGATTT \\
\hline mouse II17a sense & TCATCTGTGTCTCTGATGCTGTTG \\
\hline mouse I/17a antisense & TCGCTGCCTTCACTGT \\
\hline mouse Ifng sense & TGGCATAGATGTGGAAGAAAAGAG \\
\hline mouse Ifng antisense & TGCAGGATTITCATGTCACCAT \\
\hline mouse Foxp3 sense & TTCATGCATCAGCTCTCCAC \\
\hline mouse Foxp3 antisense & CTGGACACCCATTCCAGACT \\
\hline mouse $/ 11 b$ sense & GAAATGCCACCTITTGACAGTG \\
\hline mouse $/ / 1 \mathrm{~b}$ antisense & TGGATGCTCTCATCAGGACAG \\
\hline mouse $/ / 6$ sense & TCTATACCACTTCACAAGTCGGA \\
\hline mouse $1 / 6$ antisense & GAATTGCCATTGCACAACTCTTT \\
\hline mouse Tgfb 1 sense & CGAAGCGGACTACTATGCTAAAGA \\
\hline mouse Tgfb 1 antisense & GTITCTCATAGATGGCGTTGTTG \\
\hline mouse $/ 110$ sense & GAGAAGCATGGCCCAGAAATC \\
\hline mouse $/ / 10$ antisense & CGCATCCTGAGGGTCTTCA \\
\hline mouse $/ 112 p 40$ sense & GGTGCAAAGAAACATGGACTTG \\
\hline mouse $/ 112 p 40$ antisense & CACATGTCACTGCCCGAGAGT \\
\hline mouse II23p19 sense & GCACCAGCGGGACATATGA \\
\hline mouse I/23p19 antisense & СCTTGTGGGTCACAACCATCT \\
\hline mouse Tnfa sense & GACCCTCACACTCAGATCATCTTCT \\
\hline mouse Tnfa antisense & CCACTTGGTGGTTTGCTACGA \\
\hline mouse Il20ra sense & GGAAACTCAAGTCAGCCCAC \\
\hline mouse II2Ora antisense & AGATGGACTTCTCGCCAGTT \\
\hline mouse II2Orb sense & CCGAAATGCAACTGTCCTCAC \\
\hline mouse II2Orb antisense & AATAACCAGATGCAGCCCATGT \\
\hline mouse Rorgt sense & GCGACTGGAGGACCTTCTAC \\
\hline mouse Rorgt antisense & TCССАСАTTGACTTССТСТG \\
\hline mouse $H 2 a b 1$ sense & AGACGCCGAGTACTGGAACAGCCAGC \\
\hline mouse H2ab1 sense & CAGAGTGTTGTGGTGGTTGAGGGCCTC \\
\hline mouse Cd80 sense & САTCAAAGCTGACTTCTCTACCC \\
\hline mouse $C d 80$ antisense & GGGTIITCCCAGGTGAAGT \\
\hline mouse Cd86 sense & TCAGTGATCGCCAACTTCAG \\
\hline mouse Cd86 sense & GAAACTCTTGAGTGAAATTGAGAGG \\
\hline mouse Hprt1 sense & CAGTCAACGGGGACATAAA \\
\hline mouse Hprt1 antisense & GGGGCTGTACTGCTTAACCAG \\
\hline
\end{tabular}

more infiltration of Th17 cells in the spinal cord than WT mice (Figures 2A,B). By contrast, no difference was observed in Th1 cell infiltration between IL-19-/- and WT mice (Figure 2C). These results indicate that IL-19 deficiency mediates elevated CNS infiltration by Th17 cells, but not Th1 cells.

\section{IL-19 Deficiency Expands Th17 Cell Population}

To determine whether IL-19 contributes to the expansion of Th17 cells during the induction phase of EAE, we assessed the antigenspecific expansion of Th17 cells ex vivo. Splenic CD4 ${ }^{+} \mathrm{T}$ cells isolated from WT and IL-19-/- mice at MOG-EAE onset were stimulated with MOG peptide for 3 days in vitro. IL-19 deficiency 
A

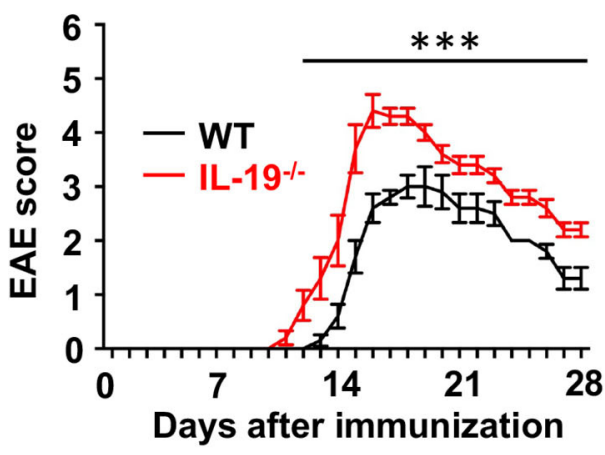

C

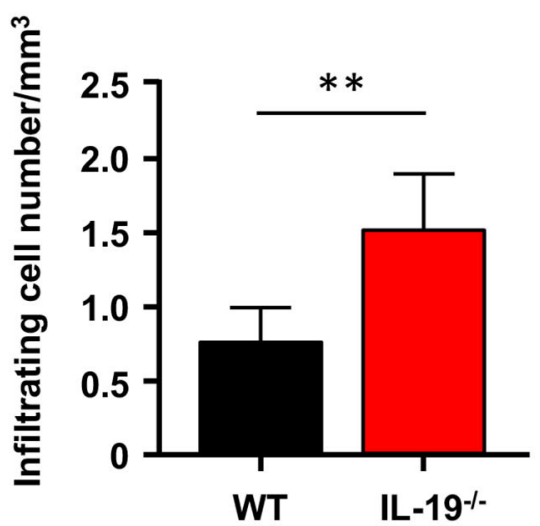

D

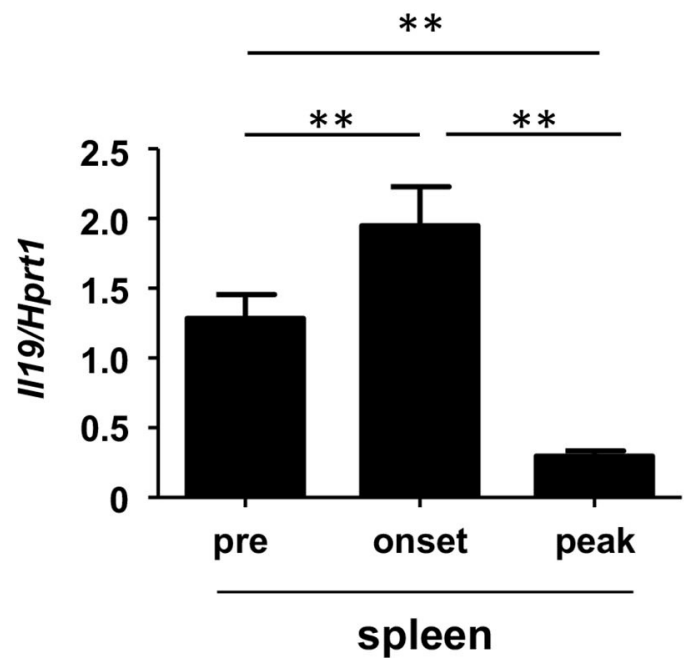

B

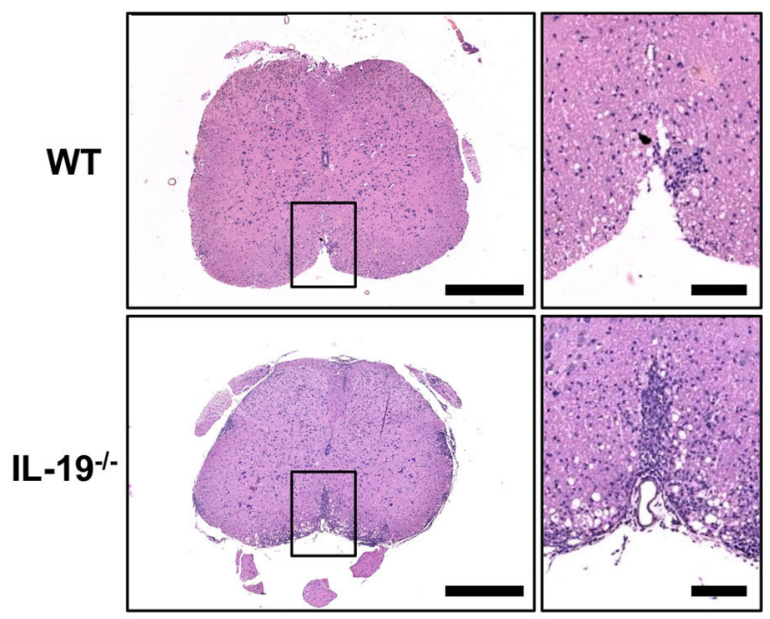

E

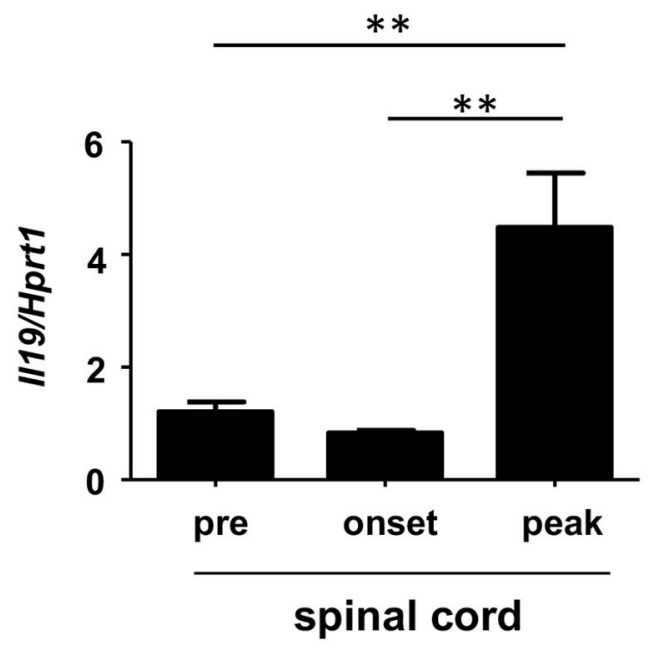

FIGURE 1 | IL-19 deficiency aggravates EAE. (A) EAE clinical scores for WT (black) and IL-19-/- (red) mice. Statistical significance was analyzed using repeated measures ANOVA followed by post-hoc Tukey's test. Data represent means $\pm S D(n=10)$. ${ }^{\star \star \star} p<0.0001$. (B) Micrographs of hematoxylin/eosin staining of $L 5$ lumbar 
FIGURE 1 | spinal cords at the peak EAE of WT and IL-19-/- mice. The right panels show enlargements of the boxed areas in the left panels. Scale bars: $500 \mu \mathrm{m}$ (left), $100 \mu \mathrm{m}$ (right). (C) Quantitative analysis of cell infiltration in L5 lumbar spinal cords at the peak EAE $(n=5)$. Statistical significance was analyzed using Student's $t$-test. Data represent means \pm SEM. ${ }^{\star \star} p<0.01$. (D) Chronological qPCR data for IL-19 mRNA expression level in the spleen of WT EAE mice ( $\left.n=5\right)$. (E)

Chronological qPCR data for IL-19 mRNA expression level in the lumbar spinal cord of WT EAE mice $(n=5)$. Pre, pre-immunization; onset, EAE onset; peak, EAE peak. Statistical significance was analyzed using one-way ANOVA followed by post-hoc Tukey's test. Data represent means \pm SD. ${ }^{* \star} p<0.01$.

A

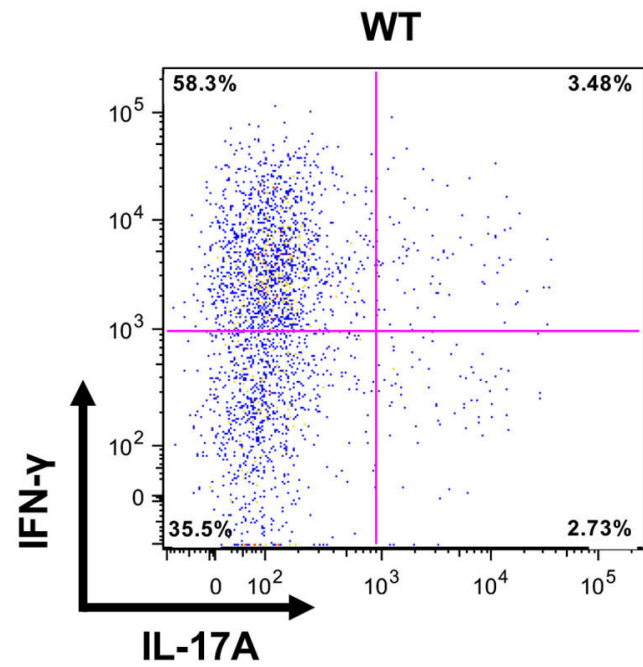

B

Th17

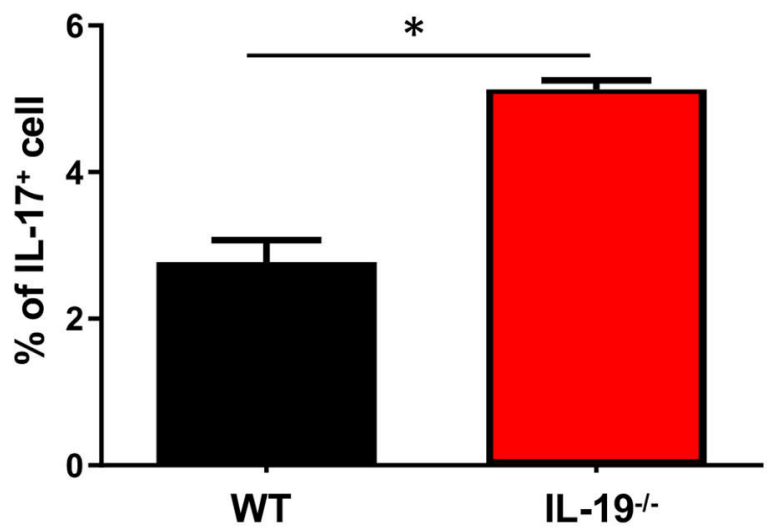

IL-19-1-

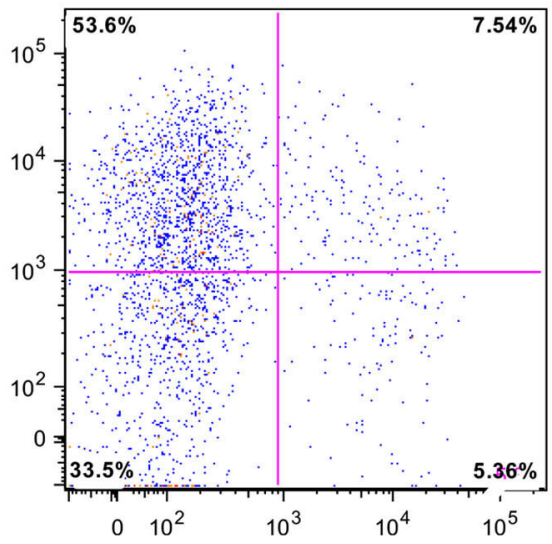

C

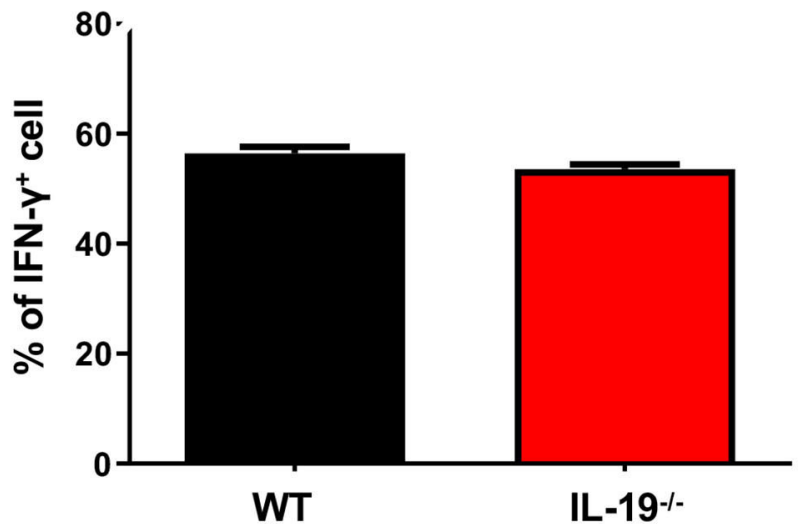

FIGURE 2 | IL-19 deficiency increases CNS infiltration of Th17 cells, but not Th1 cells. (A) Representative flow-cytometric data for IL-17- and IFN- $\gamma$-producing CD4 T cells in the CNS at the peak EAE. (B) Percentage of IL-17-producing CD4 ${ }^{+}$T cells. (C) Percentage of IFN- $\gamma$-producing CD4 ${ }^{+}$T cells. Statistical significance was analyzed using Student's $t$-test. Data represent means $\pm \operatorname{SEM}(n=3)$. ${ }^{*} p<0.05$.

significantly upregulated Il17a mRNA and downregulated Foxp3 mRNA, but it did not affect the level of Ifng mRNA (Figure 3A). Flow cytometric analysis also revealed that IL-19 deficiency expanded the Th17 cell population (Figures 3B,C). These results indicate that IL-19 deficiency mediates expansion of Th17 cells in the peripheral lymphoid tissues.

\section{IL-19 Deficiency Skews Cytokine Expression Profiles Toward Th17 Cell Expansion in Macrophages}

We then examined how IL-19 deficiency expands Th17 cells in the induction phase of EAE. First, we evaluated the mRNA expression level of IL-19 receptor (heterodimer 
A

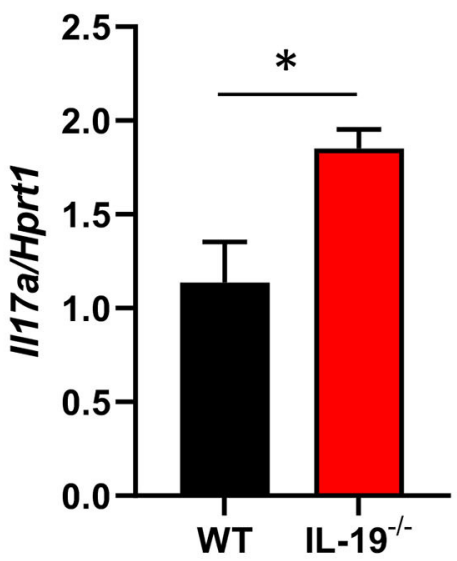

B

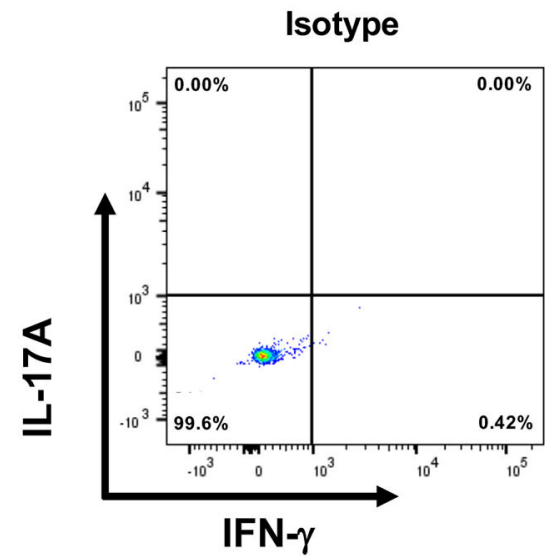

C

Th17

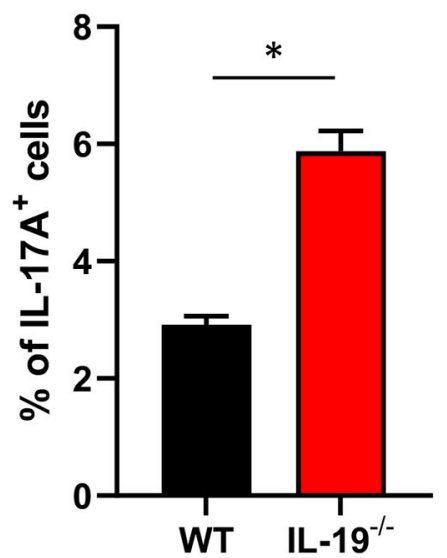

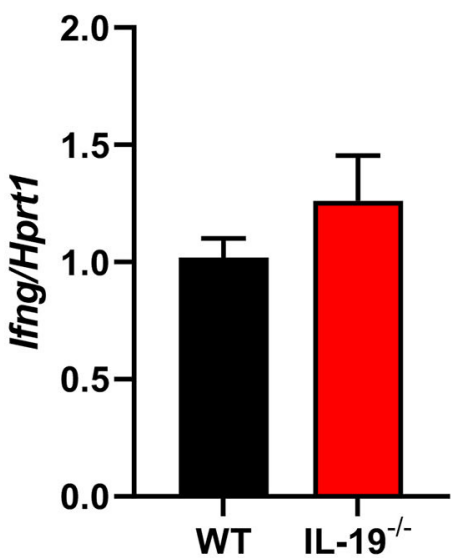
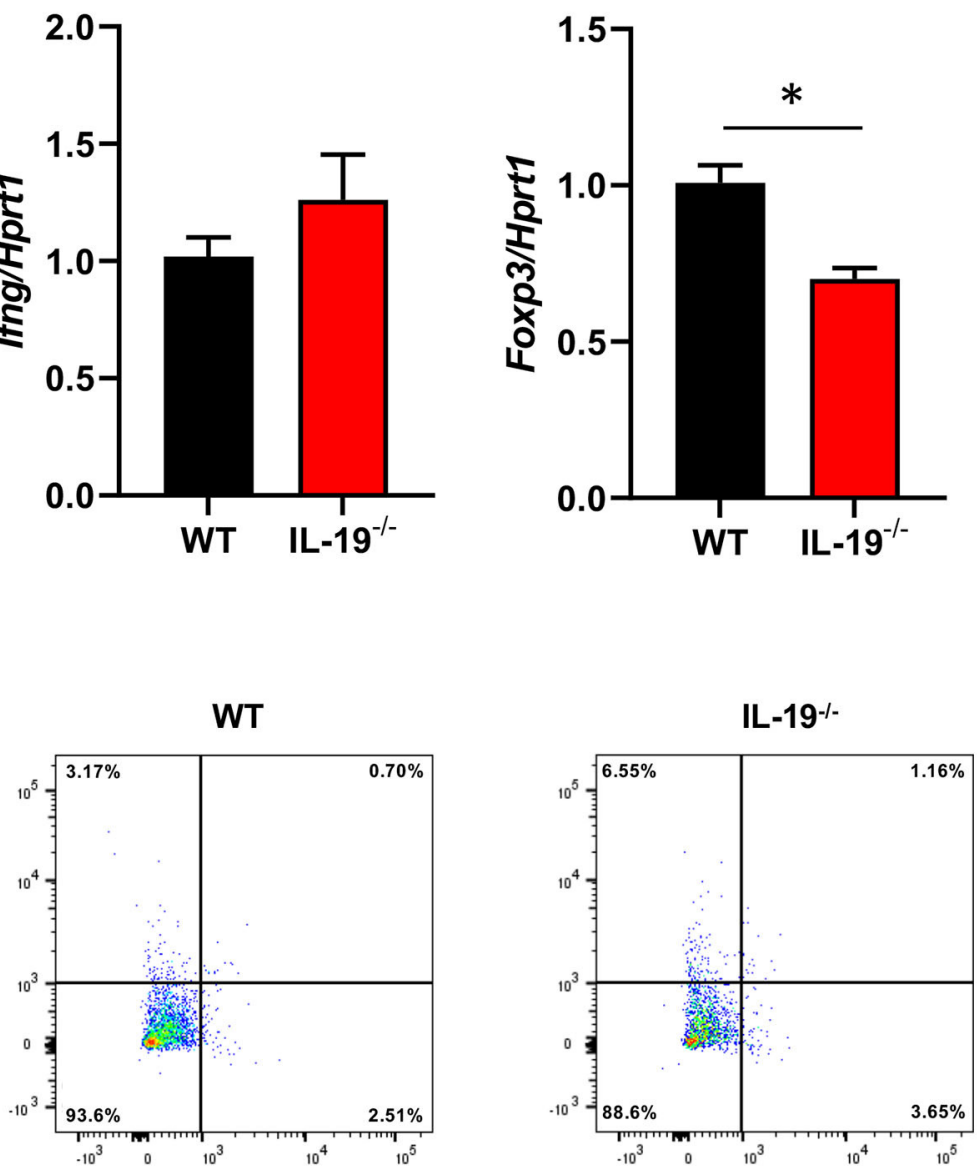

Th1

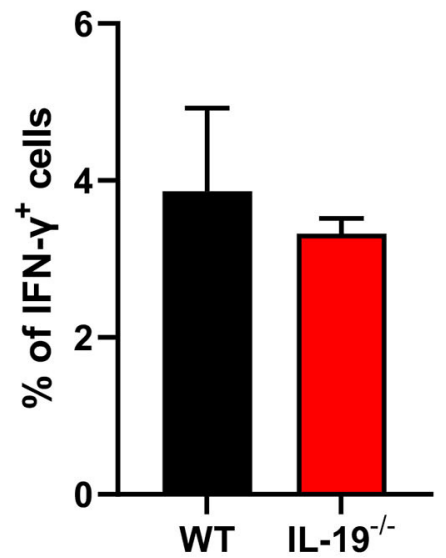

FIGURE 3 | IL-19 deficiency expands the Th17 cell population. (A) qPCR data for levels of mRNAs encoding IL-17A, IFN- $\gamma$, and FoxP3 in splenic CD4+ T cells (B) Representative flow cytometric data for IL-17 and IFN- $\gamma$-producing CD4 ${ }^{+}$T cells in the spleens of EAE mice. (C) Percentage of IL-17 and IFN- $\gamma$-producing CD4+ T cells in the spleens of EAE mice. Cells were isolated from WT and IL-19-/- EAE mice on 7 days after immunization and stimulated with MOG peptide for 3 days in vitro. Statistical significance was analyzed using Student's $t$-test. Data represent means \pm SEM $(n=3) .{ }^{*} p<0.05$. 

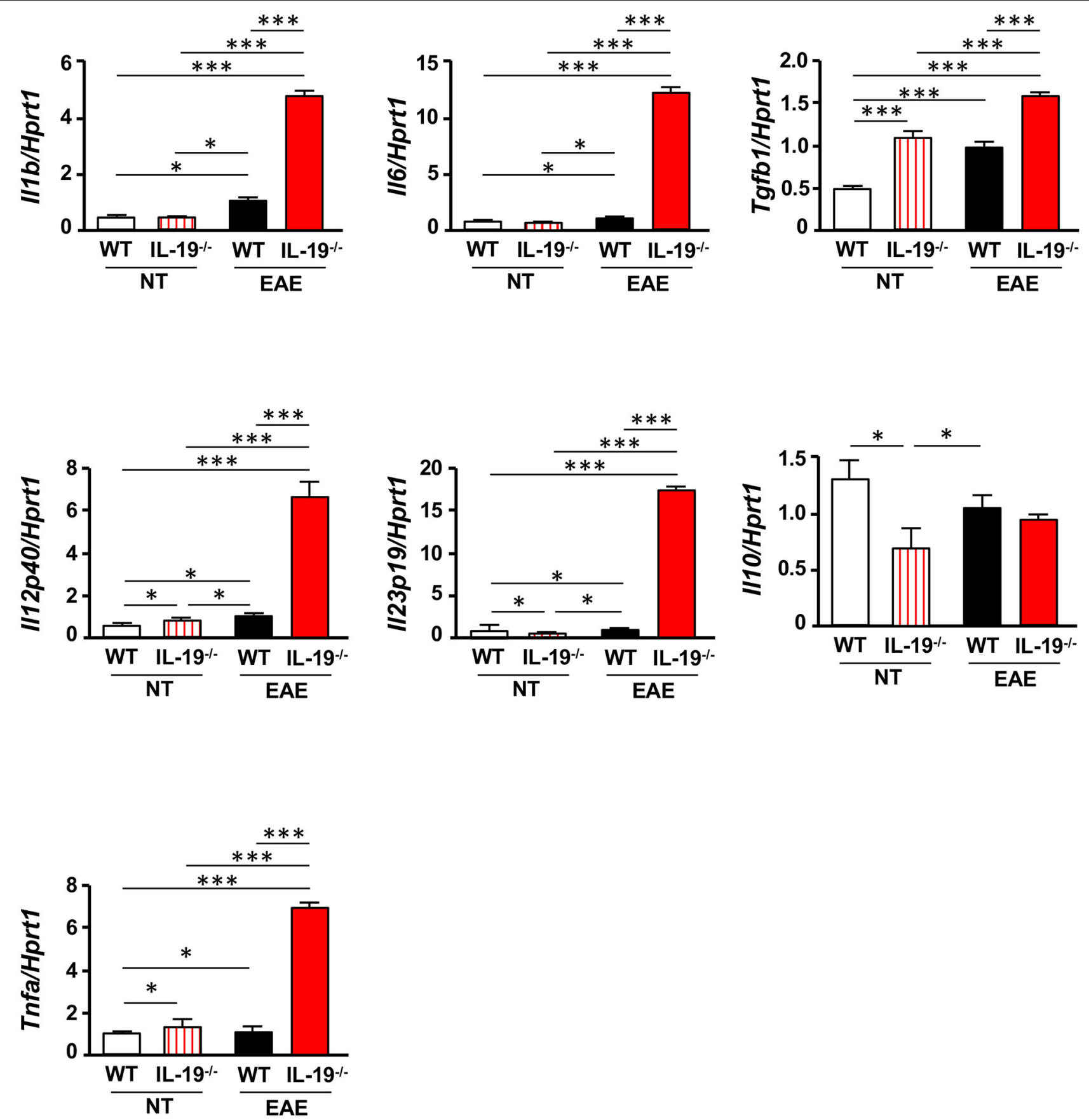

FIGURE 4 | IL-19 deficiency upregulates Th17 cell differentiation-associated cytokines in macrophages. qPCR data for mRNAs encoding IL-1 $\beta$, IL-6, TGF- $\beta 1$, IL-12 p40, IL-23 p19, IL-10, and TNF- $\alpha$ in splenic macrophages of untreated (non-immunized) mice or EAE mice. Assessments of the samples from EAE mice were performed 7 days after immunization. Statistical significance was analyzed using one-way ANOVA followed by post-hoc Tukey's test. Data represent means \pm SEM. ${ }^{\star} p<0.05 ;{ }^{\star \star \star} p<0.0001(n=6)$. NT, untreated mice.

of IL-20R $\alpha$ and IL-20R $\beta$ subunits) in the splenic immune cells such as macrophage, dendritic cell (DC), and $\mathrm{CD}^{+}$ helper $\mathrm{T}$ cell. We found that both the IL-20R $\alpha$ and IL$20 \mathrm{R} \beta$ subunits were more highly expressed in $\mathrm{CD}_{11} \mathrm{~b}^{+}$ macrophages and $\mathrm{CD}^{+}$helper $\mathrm{T}$ cells than in $\mathrm{CD}_{11 \mathrm{c}^{+}}$
DCs (Supplementary Figure 2). These results suggest that IL-19 mainly affects macrophages and $\mathrm{CD}^{+}$helper T cells.

Next, we assessed whether IL-19 directly differentiates naïve $\mathrm{CD}^{+} \mathrm{T}$ cells into Th17 cells. Naïve T cells were polarized using 


\section{A}
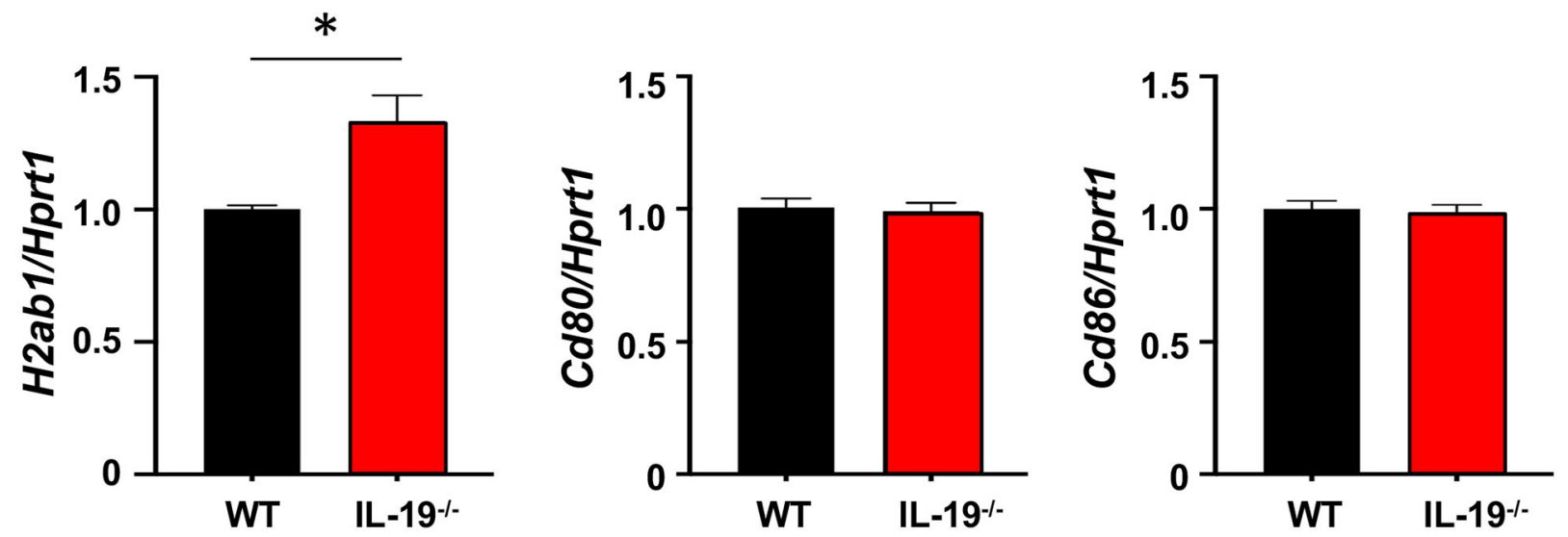

B

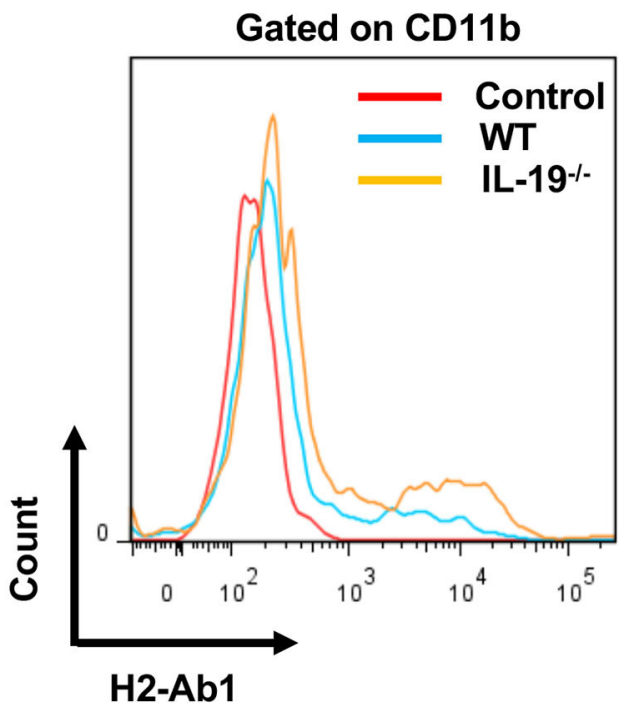

FIGURE 5 | IL-19 deficiency enhances antigen-presenting activity in macrophages. (A) qPCR data for mRNAs encoding MHC class II (H2-Ab), CD80, and CD86 in the splenic macrophages on day 7 after immunization. Data represent means \pm SD. ${ }^{*} p<0.05(n=6)$. (B) Representative flow cytometric data for MHC class $\|$ (H2-Ab) presentation in splenic macrophages.

immobilized CD3 and CD28 antibodies in the presence of IL-6 and transforming growth factor $\beta 1$ (TGF- $\beta 1$ ), with or without IL19. Quantitative PCR (qPCR) and flow cytometry revealed that IL-19 did not alter the differentiation of naive T cells into Th17 cells (Supplementary Figure 3).

Because antigen-presenting cells (APCs) are crucial for differentiation of naïve $\mathrm{T}$ cells into effector $\mathrm{T}$ cells, we evaluated the expression levels of cytokines required for Th17 cell expansion in splenic macrophages and DCs. Interestingly, IL$19^{-/-}$macrophages from EAE mice exhibited a significant increase in mRNA levels of the genes encoding IL-1 $\beta$, IL-6, TGF- $\beta 1$, IL-12 p40, IL-23 p19, and tumor necrosis factor $\alpha$ (TNF- $\alpha)$, which play pivotal roles in Th17 cell differentiation and expansion (Figure 4). Although a previous study showed that IL-19 increases IL-10 expression (32), our data showed that IL-19 deficiency did not alter the Il10 mRNA level in macrophages in EAE whereas IL-19 deficiency downregulated Illo mRNA expression in non-immunized macrophages (Figure 4). By contrast, IL-19-/- DCs did not exhibit a significant alteration in the expression levels of these 
A

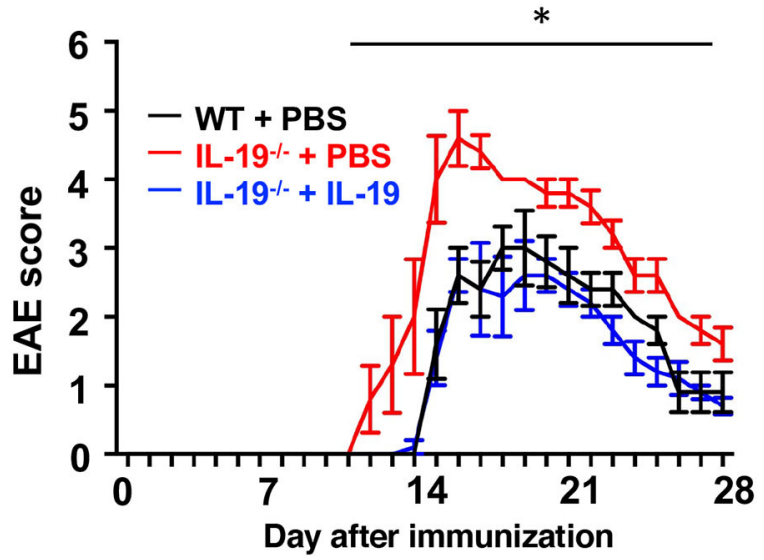

B

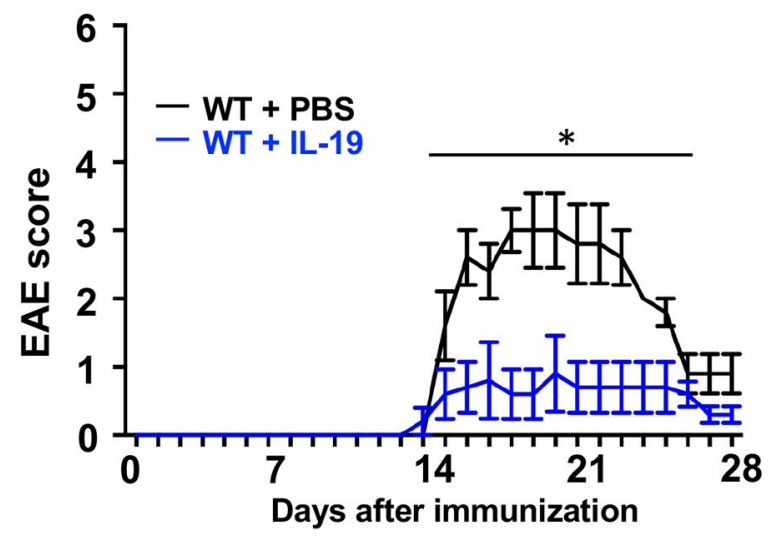

IL-19-- + PBS

IL-19-1- + IL-19

C

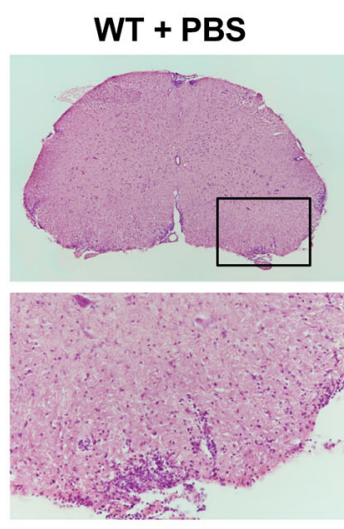

WT + IL-19
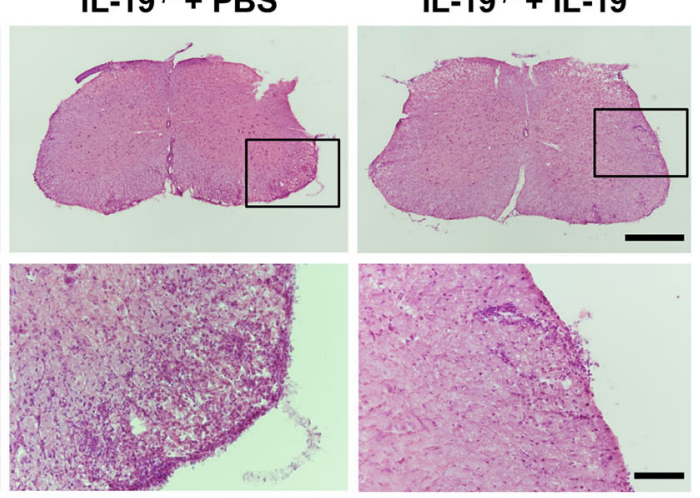

D

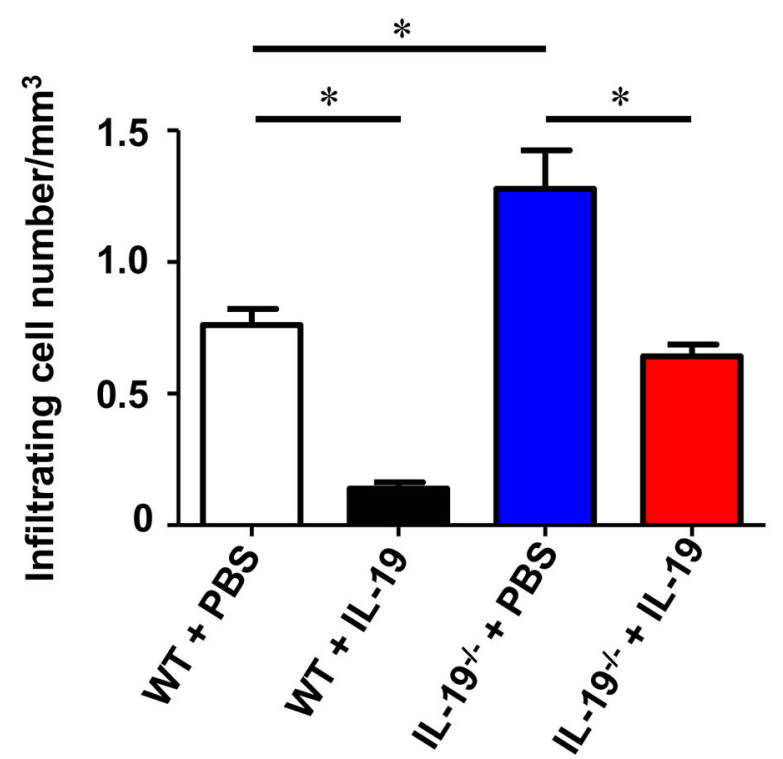

FIGURE 6 | Treatment with recombinant IL-19 alleviates EAE. (A) EAE clinical score. WT + PBS (black): WT EAE mice treated with PBS; IL-19-/- + PBS (red): IL-19-/- EAE mic treated with PBS; IL-19-/- + IL-19 (blue): IL-19-/- EAE mice treated with IL-19. (B) EAE clinical score. WT + PBS (black), WT EAE micee 
FIGURE 6 | treated with PBS; WT + IL-19 (blue), WT EAE mice treated with IL-19. Statistical significance was analyzed using repeated measures ANOVA followed by post-hoc Tukey's test. Data represent means \pm SD. ${ }^{*} p<0.05(n=5)$. (C) Micrographs of hematoxylin/eosin staining of L5 lumbar spinal cords of EAE mice. The bottom panels show enlargements of the boxed areas in the upper panels. Scale bars: $500 \mu \mathrm{m}$ (upper), $100 \mu \mathrm{m}$ (bottom). (D) Quantitative analysis of cell infiltration in L5 lumbar spinal cords at the peak EAE $(n=5)$. Statistical significance was analyzed using repeated one-way ANOVA followed by post-hoc Tukey's test. Data represent means \pm SEM. ${ }^{*} p<0.05$.

cytokines (Supplementary Figure 4). These findings indicated that IL-19 deficiency skews the cytokine expression profiles toward Th17 cell differentiation and expansion in macrophages. Conversely, our data suggested that IL-19 suppresses Th17skewed condition by activating macrophages.

\section{IL-19 Deficiency Promotes MHC Class II Expression in Macrophages}

To determine whether IL-19 signaling contributes to antigen presentation by macrophages, we assessed the expression of major histocompatibility complex (MHC) class II (H2-Ab) and co-stimulatory molecules (CD80 and CD86) in splenic $\mathrm{CD}_{11 b^{+}}$macrophages from WT and IL-19-/- EAE mice (Figure 5A). IL-19 deficiency significantly enhanced expression of the gene encoding MHC class II, whereas the genes encoding co-stimulatory molecules CD80 and CD86 were not affected (Figure 5A). Flow cytometric data corroborated the enhanced presentation of MHC class II in IL-19-/- splenic macrophages (Figure 5B). These observations suggested that IL-19 also suppresses the antigen-presenting activity of macrophages.

\section{Treatment With IL-19 Abrogates EAE}

Then, we examined whether exogenous IL-19 abolishes the effect of IL-19 deficiency in EAE. According to the previous studies showing that the daily administration of IL-19 protein $(10 \mathrm{ng} / \mathrm{g}$ of body weight) can offset IL-19 deficiency $(29,30)$, we firstly treated WT and IL-19-/- EAE mice with recombinant mouse IL-19 protein (10 ng/g of body weight) or PBS by intraperitoneal injection every day. However, even daily injection with PBS caused mice severe stress which markedly suppressed EAE development (33). Therefore, we decided to treat mice every other day because this frequency of treatment did not cause mice enough stress to suppress EAE. We treated IL-19-/- EAE mice with recombinant mouse IL-19 protein $(20 \mathrm{ng} / \mathrm{g}$ of body weight) by intraperitoneal injection every other day, starting on day 2 post-immunization. As expected, administration of IL-19 to IL-19-/- mice improved EAE to the similar level to WT EAE mice, indicating that IL-19 treatment completely offset the effect of IL-19 deficiency (Figure 6A, IL-19-/- + IL-19). Limitations of solubility and injection volume did not allow us to increase the dosage. We then investigated the therapeutic effect of IL19 on EAE. When we treated WT EAE mice with recombinant mouse IL-19 protein in the same manner (i.e., their IL-19 level were estimated twice as much as the baseline level in untreated WT mice), we found that IL-19 treatment almost completely inhibited EAE (Figure 6B). Histological analysis revealed that the clinical improvement accorded with the level of inflammatory cell infiltration in the lumbar spinal cords (Figures 6C,D). These results indicated that IL-19 represents a potential target for MS therapy.

\section{Treatment With IL-19 Did Not Alter Macrophage Phenotype}

To determine whether IL-19 treatment converts macrophage phenotype, we assessed macrophage M1/M2 phenotype by immunofluorescent staining for iNOS (M1 marker) and arginase 1 (M2 marker) in the infiltrating macrophage $\left(\mathrm{F} 4 / 80^{+}\right)$. Immunostaining data revealed that IL-19 treatment did not alter M1/M2 macrophage population although infiltrating $\mathrm{F} 4 / 80^{+}$ macrophage were not detected in IL-19-treated WT EAE mice (Figure 7). These observations suggested that main therapeutic effect of IL-19 on EAE is suppression of inflammatory cell infiltration in the CNS, but not M1/M2 phenotype conversion.

\section{DISCUSSION}

IL-19 has been considered to be a Th2 cytokine that promotes Th2-skewed diseases such as asthma, atopic dermatitis, psoriasis, and rheumatoid arthritis (34), however, IL-19 often exerts controversial effects depending on species and types of immune cells (35). In inflammatory bowel disease, IL-19 exerts antiinflammatory effect to hamper hyperactivation of both innate and acquired immunity $(11,23)$. As to asthma, in human and murine models, IL-19 exacerbates the disease by a positivefeedback on Th2 cells and M2 macrophage via upregulation of such Th2 cytokines as IL-4, IL-5, IL-10, and IL-13 (18, 19, 32, 36), whereas IL-19 also promotes M1 macrophage by upregulation of such Th1 cytokines as IL- 6 and TNF- $\alpha$ (37). Although this dichotomy in response to IL-19 may partially derive from the differences in phenotype of mice used (i.e., Th1skewed C57BL/6 mice vs. Th2-skewed BALB/c mice), a growing evidence suggests that IL-19 exerts pleiotropic roles in both pro- and anti-inflammatory responses among different types of immune cells.

In this study, we demonstrated that endogenous IL19 negatively regulates development of EAE by inhibiting macrophage activation, and that IL-19 treatment effectively abrogates EAE. As shown in Figures 1D,E, endogenous Il19 mRNA expression was upregulated at EAE onset and downregulated at EAE peak in the spleen, whereas it was elevated at EAE peak in the CNS. We have previously identified IL-19 as a negative-feedback regulator to limit proinflammatory response of macrophages and microglia in autocrine/paracrine manners $(11,12)$. From this point of view, these data imply that endogenous IL-19 increases to suppress inflammation accompanied by macrophage/microglia activation as disease progresses from the periphery to CNS, although it is insufficient to halt EAE progression. It is also intriguing that splenic Il19 mRNA expression decreased at EAE peak much less than at pre-immunization. A previous study showed that IL-19 increases 
A
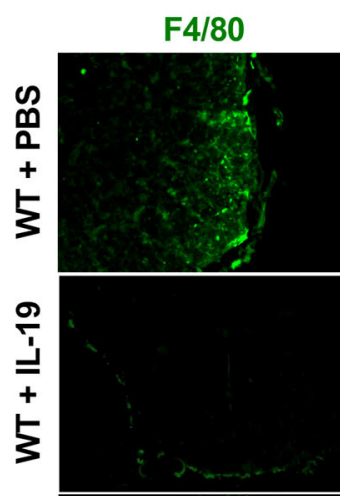

m

ณ

$+$

$\frac{1}{5}$

'

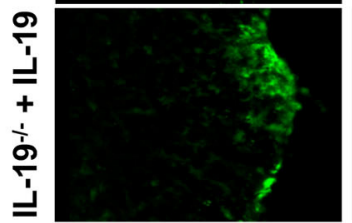

C
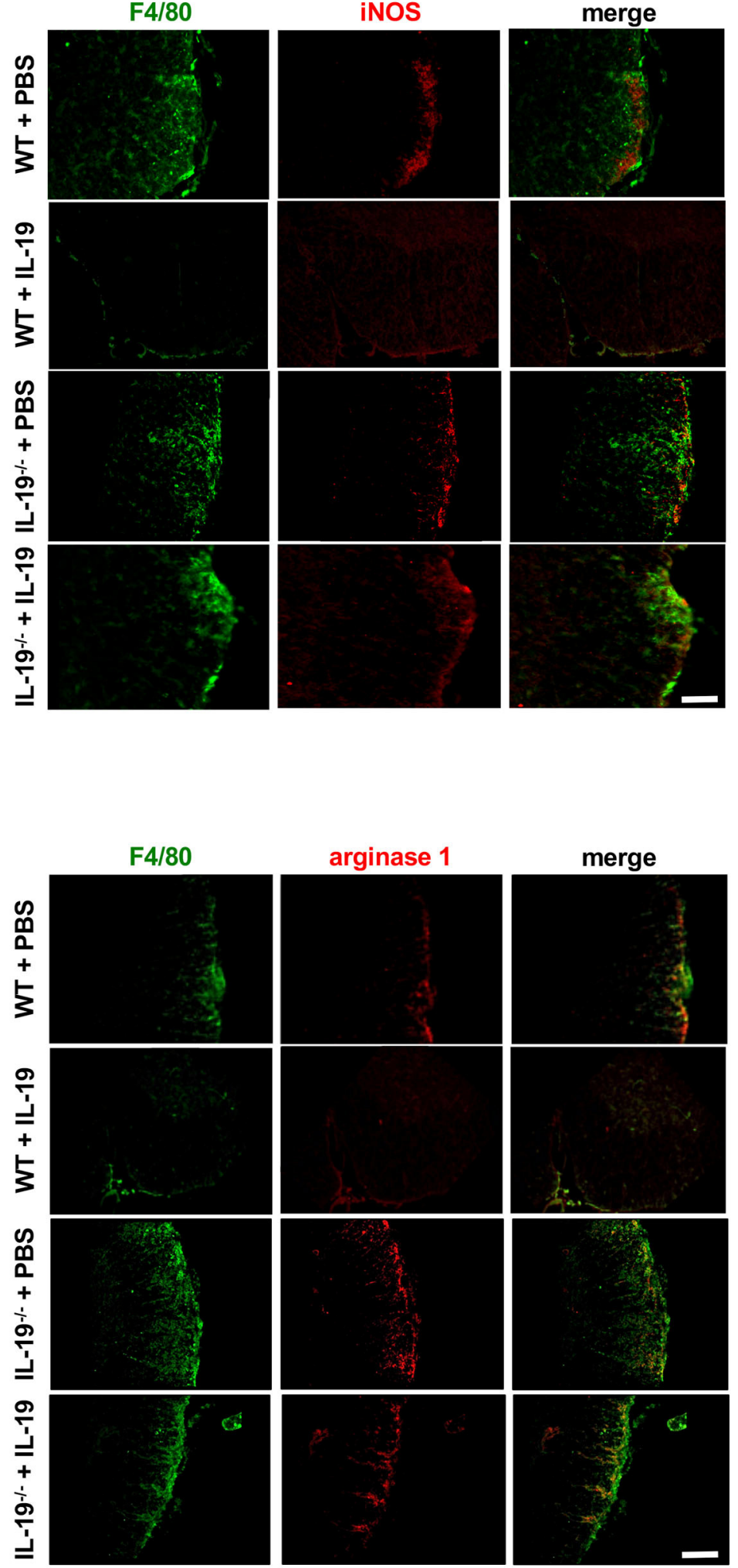

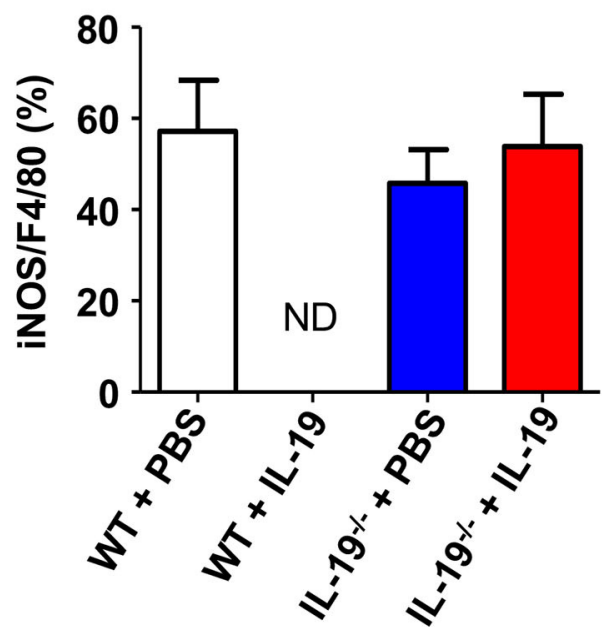

D

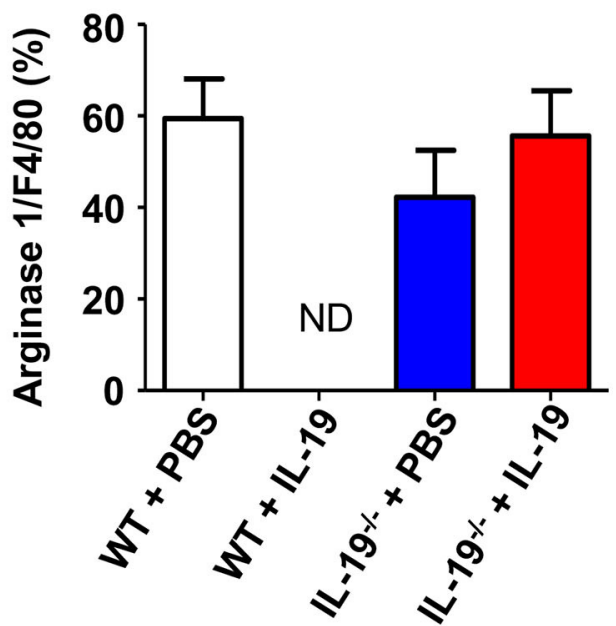

FIGURE 7 | Treatment with recombinant IL-19 did not alter macrophage phenotype. (A) Representative immunohistological images of L5 lumbar spinal cord sections from EAE mice. Pro-inflammatory M1 macrophage (iNOS) were examined. (B) Quantitative data of A. IL-19 treatment did not alter the number of iNOS ${ }^{+}$F4/80+ M1

(Continued) 
FIGURE 7 | cells albeit F4/80+ cells were not detected in IL-19-treated WT EAE mice. (C) Representative immunohistological images of L5 lumbar spinal cord sections from EAE mice. Anti-inflammatory M2 macrophage (arginase 1) were examined. (D) Quantitative data of (C). IL-19 treatment did not alter M1/M2 cell population although $\mathrm{F}_{4} / 80^{+}$cells were not detected in IL-19-treated WT EAE mice. Scale bars, $100 \mu \mathrm{m}$. Statistical significance was analyzed using repeated measures ANOVA followed by post-hoc Tukey's test. Data represent means \pm SEM $(n=5)$. ND, not detected.

IL-10 which downregulates IL-19, suggesting that IL-10 is a negative-feedback regulator of IL-19 (32). In accordance with this fact, our qPCR data also showed that IL-19 deficiency downregulated Il10 mRNA expression (Figure 4). Since IL-10 increases during recovery phase of EAE (38), it is plausible that IL-19-induced IL-10 downregulates splenic IL-19 at the peak EAE. Accordingly, axis of IL-19 and IL-10 may be a critical inducer of remission in MS. In fact, a recent study disclosed that serum IL-19 levels were lower in the relapse phase than the remission phase in patients with neuromyelitis optica (39).

Th17 cell infiltration in the CNS is considered critical for the development of $\operatorname{EAE}(5,40)$, and APCs such as macrophages, microglia, and DC are also essential for effector $T$ cell differentiation and expansion in EAE (41). Specifically, IL-1 $\beta$, IL-6, IL-23, TGF- $\beta 1$, and TNF- $\alpha$ released by APCs play pivotal roles in Th17 cell differentiation and expansion (5, 31, 42-45). In this study, we revealed that IL-19 deficiency significantly upregulated mRNA levels of these Th17 cell differentiation-associated cytokines in macrophages, but not in DCs (Figure 4 and Supplementary Figure 3), although these protein levels have not been evaluated in this study. These phenomena were correlated with the expression level of IL-19 receptor (IL-20R $\alpha$ and IL-20R $\beta$ heterodimer), which was highly expressed in macrophages, but not in DCs or helper $\mathrm{T}$ cells (Supplementary Figure 1). IL-19 deficiency further enhanced MHC class II expression in macrophages, which enable to prime $\mathrm{T}$ cells (46). Taken together, our findings suggest that IL-19 suppresses Th17 cell differentiation and expansion by suppressing cytokine production and antigen presentation in macrophages. Interestingly, a previous study reported that IL17A induces IL-19 production (19). Thus, IL-19 also might serve as a negative regulator of further Th17 cell polarization.

In addition, activated macrophages and microglia directly contribute to neuroinflammation-induced demyelination by releasing proinflammatory cytokines such as IL-1 $\beta$, IL-6, and TNF- $\alpha$ (41, 47-49). In our study, IL-19 deficiency increased the levels of these proinflammatory cytokines in macrophages and exacerbated EAE until the late phase of the disease. We previously revealed that IL-19 secreted from activated macrophages and microglia suppressed their proinflammatory responses in an autocrine/paracrine manner $(11,12)$. Therefore, IL-19 might suppress development of EAE by dual inhibition of both autoreactive Th17 cell expansion and macrophage/microgliamediated CNS neuroinflammation.

While IL-19 shares its receptor IL-20R $\alpha$ and IL-20R $\beta$ with IL20 and IL-24, IL-20 and IL-24 also bind another heterodimer receptor IL-22R $\alpha 1$ and IL-20R $\beta$ (50). Therefore, these cytokines have unique biological functions as well as common functions including promoting Th2-skew inflammation. For example, unlike IL-19, IL-20 promotes DC cell maturation (51) and
IL-24 exerts antitumorigenic effects (52). It is still uncertain whether these unique functions depend on the restricted expression pattern of their receptors or the synergistic effects of downstream signaling pathways (50). Although the IL19 signaling pathway has not been fully elucidated, IL19 mediates its downstream signaling at least by STAT3 activation $(8,9,12,53)$. However, it remains controversial whether STAT3 activation is beneficial or harmful with regard to autoimmune-mediated neuroinflammation. Previous studies also reported that STAT3 activation in myeloid cells (including macrophages and microglia) exacerbates EAE (54, 55). By contrast, STAT3 ablation worsens neuroinflammation in mice with spinal cord injury (56), and STAT3 activation alleviates cuprizone-induced CNS demyelination (57). This discordancy may depend on spatiotemporally specific activation of STAT3 (58). Indeed, in contrast to macrophages, IL-19 deficiency did not affect activation of DCs. Recent clinical trials of JAK/STAT inhibitors for autoimmune diseases have revealed a complicated signal network of cytokine/STAT axes in multiple cell types (59). Further studies are needed to elucidate the precise IL-19 signaling pathway in each cell type.

\section{CONCLUSIONS}

In this study, we revealed that IL-19 deficiency exacerbated EAE by upregulating Th17 cell differentiation-associated cytokines and enhancing antigen presentation in macrophages, followed by Th17 cell expansion and infiltration in the CNS. We also demonstrated that IL-19 administration potently prevented development of EAE. Therefore, enhancement of IL-19 signaling represents a promising therapeutic strategy against MS and other Th17-mediated autoimmune diseases.

\section{DATA AVAILABILITY STATEMENT}

The raw data supporting the conclusions of this article will be made available by the authors, without undue reservation.

\section{ETHICS STATEMENT}

The animal study was reviewed and approved by Animal Experiment Committee of Nagoya University and Yokohama City University.

\section{AUTHOR CONTRIBUTIONS}

$\mathrm{HH}, \mathrm{BP}, \mathrm{AS}$, and HT designed the research. HH, BP, HK, YO, SJ, KT, Y-TA, and HT performed the research. HH, BP, HK, FT, 
AS, and HT analyzed the data. and HH, BP, and HT wrote the paper. All authors contributed to the article and approved the submitted version.

\section{FUNDING}

This work was supported by grants-in-aid for Scientific Research from the Ministry of Education, Culture, Sports, Science and Technology of Japan (HT); grants from the Ministry of Health, Labour and Welfare of Japan (AS and HT); the Program for Promotion of Fundamental Studies in Health Sciences of the National Institute of Biomedical

\section{REFERENCES}

1. Hemmer B, Archelos JJ, Hartung HP. New concepts in the immunopathogenesis of multiple sclerosis. Nat Rev Neurosci. (2002) 3:291-301. doi: 10.1038/nrn784

2. Filippi M, Bar-Or A, Piehl F, Preziosa P, Solari A, Vukusic S, et al. Multiple sclerosis. Nat Rev Dis Primers. (2018) 4:43. doi: 10.1038/s41572-018-0041-4

3. Waisman A, Hauptmann J, Regen T. The role of IL-17 in CNS diseases. Acta Neuropathol. (2015) 129:625-37. doi: 10.1007/s00401-015-1402-7

4. Takeuchi H. Midkine and multiple sclerosis. Brit J Pharmacol. (2014) 171:9315. doi: 10.1111/bph.12499

5. Bettelli E, Carrier Y, Gao W, Korn T, Strom TB, Oukka M, et al. Reciprocal developmental pathways for the generation of pathogenic effector TH17 and regulatory T cells. Nature. (2006) 441:235-8. doi: 10.1038/nature04753

6. Gallagher G, Dickensheets H, Eskdale J, Izotova LS, Mirochnitchenko OV, Peat JD, et al. Cloning, expression and initial characterisation of interleukin-19 (IL-19), a novel homologue of human interleukin-10 (IL-10). Genes Immun. (2000) 1:442-50. doi: 10.1038/sj.gene.6363714

7. Gallagher G, Eskdale J, Jordan W, Peat J, Campbell J, Boniotto M, et al. Human interleukin-19 and its receptor: a potential role in the induction of Th2 responses. Int Immunopharmacol. (2004) 4:615-26. doi: 10.1016/j.intimp.2004.01.005

8. Nagalakshmi ML, Murphy E, McClanahan T, de Waal Malefyt, R. Expression patterns of IL-10 ligand and receptor gene families provide leads for biological characterization. Int Immunopharmacol. (2004) 4:577-92. doi: 10.1016/j.intimp.2004.01.007

9. Dumoutier L, Leemans C, Lejeune D, Kotenko SV, Renauld JC. Cutting edge: STAT activation by IL-19, IL-20 and mda-7 through IL20 receptor complexes of two types. J Immunol. (2001) 167:3545-9. doi: 10.4049/jimmunol.167.7.3545

10. Wolk K, Witte K, Witte E, Proesch S, Schulze-Tanzil G, Nasilowska K, et al. Maturing dendritic cells are an important source of IL-29 and IL-20 that may cooperatively increase the innate immunity of keratinocytes. J Leukoc Biol. (2008) 83:1181-93. doi: 10.1189/jlb.0807525

11. Azuma YT, Matsuo Y, Kuwamura M, Yancopoulos GD, Valenzuela DM, Murphy AJ, et al. Interleukin-19 protects mice from innate-mediated colonic inflammation. Inflamm Bowel Dis. (2010) 16:1017-28. doi: 10.1002/ibd.21151

12. Horiuchi H, Parajuli B, Wang Y, Azuma YT, Mizuno T, Takeuchi H, et al. Interleukin-19 acts as a negative autocrine regulator of activated microglia. PLoS ONE. (2015) 10:e0118640. doi: 10.1371/journal.pone.0118640

13. Cooley ID, Chauhan VS, Donneyz MA, Marriott I. Astrocytes produce IL-19 in response to bacterial challenge and are sensitive to the immunosuppressive effects of this IL-10 family member. Glia. (2014) 62:81828. doi: 10.1002/glia.22644

14. Myles IA, Fontecilla NM, Valdez PA, Vithayathil PJ, Naik S, Belkaid Y, et al. Signaling via the IL-20 receptor inhibits cutaneous production of IL- $1 \beta$ and IL-17A to promote infection with methicillin-resistant Staphylococcus aureus. Nat Immunol. (2013) 14:804-11. doi: 10.1038/ni.2637

15. Ellison S, Gabunia K, Richards JM, Kelemen SE, England RN, Rudic D, et al. IL-19 reduces ligation-mediated neointimal hyperplasia by reducing
Innovation (NIBIO) of Japan (AS); and a grant from the Naito Foundation (HT).

\section{ACKNOWLEDGMENTS}

This manuscript has been released as a pre-print at bioRxiv (60).

\section{SUPPLEMENTARY MATERIAL}

The Supplementary Material for this article can be found online at: https://www.frontiersin.org/articles/10.3389/fimmu. 2021.615898/full\#supplementary-material

vascular smooth muscle cell activation. Am J Pathol. (2014) 184:2134-43. doi: 10.1016/j.ajpath.2014.04.001

16. Wahl C, Müller W, Leithäuser F, Adler G, Oswald F, Reimann J, et al. IL20 receptor 2 signaling down-regulates antigen-specific $\mathrm{T}$ cell responses. $J$ Immunol. (2009) 182:802-10. doi: 10.4049/jimmunol.182.2.802

17. Oral HB, Kotenko SV, Yilmaz M, Mani O, Zumkehr J, Blaser K, et al. Regulation of $\mathrm{T}$ cells and cytokines by the interleukin-10 (IL-10)-family cytokines IL-19, IL-20, IL-22, IL-24 and IL-26. Eur J Immunol. (2006) 36:3808. doi: 10.1002/eji.200425523

18. Liao SC, Cheng YC, Wang YC, Wang CW, Yang SM, Yu CK, et al. IL-19 induced Th2 cytokines and was up-regulated in asthma patients. J Immunol. (2004) 173:6712-8. doi: 10.4049/jimmunol.173.11.6712

19. Huang F, Wachi S, Thai P, Loukoianov A, Tan K, Forteza R, et al. Potentiation of IL-19 expression in airway epithelia by IL-17A and IL-4/IL-13: important implications in asthma. J Allergy Clin Immunol. (2008) 121:141521. doi: 10.1016/j.jaci.2008.04.016

20. Kunz S, Wolk K, Witte E, Witte K, Doecke WD, Volk HD, et al. Interleukin (IL)-19, IL-20 and IL-24 are produced by and act on keratinocytes and are distinct from classical ILs. Exp Dermatol. (2006) 15:991-1004. doi: 10.1111/j.1600-0625.2006.00516.x

21. Ghoreschi K, Thomas P, Breit S, Dugas M, Mailhammer R, van Eden W, et al. Interleukin-4 therapy of psoriasis induces Th2 responses and improves human autoimmune disease. Nat Med. (2003) 9:40-6. doi: 10.1038/nm804

22. Chan JR, Blumenschein W, Murphy E, Diveu C, Wiekowski M, Abbondanzo S, et al. IL-23 stimulates epidermal hyperplasia via TNF and IL-20R2dependent mechanisms with implications for psoriasis pathogenesis. $J$ Exp Med. (2006) 203:2577-87. doi: 10.1084/jem.20060244

23. Fonseca-Camarillo G, Furuzawa-Carballeda J, Granados J, YamamotoFurusho JK. Expression of interleukin (IL)-19 and IL-24 in inflammatory bowel disease patients: a cross-sectional study. Clin Exp Immunol. (2014) 177:64-75. doi: 10.1111/cei.12285

24. Sakurai N, Kuroiwa T, Ikeuchi H, Hiramatsu N, Maeshima A, Kaneko Y, et al. Expression of IL-19 and its receptors in RA: potential role for synovial hyperplasia formation. Rheumatology (Oxford). (2008) 47:815-20. doi: 10.1093/rheumatology/ken061

25. Barrett JC, Clayton DG, Concannon P, Akolkar B, Cooper JD, Erlich HA, et al. Genome-wide association study and meta-analysis find that over 40 loci affect risk of type 1 diabetes. Nat Genet. (2009) 41:703-7. doi: 10.1038/ng.381

26. Wang J, Takeuchi H, Sonobe Y, Jin S, Mizuno T, Miyakawa S, et al. Inhibition of midkine alleviates experimental autoimmune encephalomyelitis through the expansion of regulatory T cell population. Proc Natl Acad Sci USA. (2008) 105:3915-20. doi: 10.1073/pnas.0709592105

27. Shimojima C, Takeuchi H, Jin S, Parajuli B, Hattori H, Suzumura A, et al. Conditioned medium from the stem cells of human exfoliated deciduous teeth ameliorates experimental autoimmune encephalomyelitis. J Immunol. (2016) 196:4164-71. doi: 10.4049/jimmunol.1501457

28. Zhou Y, Sonobe Y, Akahori T, Jin S, Kawanokuchi J, Noda M, et al. IL9 promotes Th17 cell migration into the central nervous system via CC chemokine ligand-20 produced by astrocytes. J Immunol. (2011) 186:4415-21. doi: $10.4049 /$ jimmunol.1003307 
29. Richards J, Gabunia K, Kelemen SE, Kako F, Choi ET, Autieri MV. Interleukin19 increases angiogenesis in ischemic hind limbs by direct effects on both endothelial cells and macrophage polarization. J Mol Cell Cardiol. (2015) 79:21-31. doi: 10.1016/j.yjmcc.2014.11.002

30. Guo J, Wang H, Li L, Yuan Y, Shi X, Hou S. Treatment with IL-19 improves locomotor functional recovery after contusion trauma to the spinal cord. $\mathrm{Br} \mathrm{J}$ Pharmacol. (2018) 175:2611-21. doi: 10.1111/bph.14193

31. Chung Y, Chang SH, Martinez GJ, Yang XO, Nurieva R, Kang HS, et al. Critical regulation of early Th17 cell differentiation by interleukin-1 signaling. Immunity. (2009) 30:576-87. doi: 10.1016/j.immuni.2009.02.007

32. Jordan WJ, Eskdale J, Boniotto M, Lennon GP, Peat J, Campbell JD, et al. Human IL-19 regulates immunity through auto-induction of IL-19 and production of IL-10. Eur J Immunol. (2005) 35:1576-82. doi: $10.1002 /$ eji.200425317

33. Bukilica M, Djordjević S, Marić I, Dimitrijević M, Marković BM, Janković BD. Stress-induced suppression of experimental allergic encephalomyelitis in the rat. Int J Neurosci. (1991) 59:167-75. doi: 10.3109/00207459108985460

34. Nakayama T, Hirahara K, Onodera A, Endo Y, Hosokawa H, Shinoda K, et al. Th2 cells in health and disease. Annu Rev Immunol. (2017) 35:53-84. doi: 10.1146/annurev-immunol-051116-052350

35. Chen J, Caspi RR, Chong WP. IL-20 receptor cytokines in autoimmune diseases. J Leukoc Biol. (2018) 104:953-9. doi: 10.1002/JLB.MR1117-471R

36. Weng YH, Chen WY, Lin YL, Wang JY, Chang MS. Blocking IL-19 signaling ameliorates allergen-induced airway inflammation. Front Immunol. (2019) 10:968. doi: 10.3389/fimmu.2019.00968

37. Liao YC, Liang WG, Chen FW, Hsu JH, Yang JJ, Chang MS. IL-19 induces production of IL-6 and TNF-alpha and results in cell apoptosis through TNFalpha. J Immunol. (2002) 169:4288-97. doi: 10.4049/jimmunol.169.8.4288

38. Kennedy MK, Torrance DS, Picha KS, Mohler KM. Analysis of cytokine mRNA expression in the central nervous system of mice with experimental autoimmune encephalomyelitis reveals that IL-10 mRNA expression correlates with recovery. J Immunol. (1992) 149:2496-505.

39. Wang Y, Zhou Y, Sun X, Lu T, Wei L, Fang L, et al. Cytokine and chemokine profiles in patients with neuromyelitis optica spectrum disorder. Neuroimmunomodulation. (2016) 23:352-8. doi: 10.1159/000464135

40. Xu Y, He Z, Li Z, Fang S, Zhang Y, Wan C, et al. Irgm1 is required for the inflammatory function of M1 macrophage in early experimental autoimmune encephalomyelitis. J Leukoc Biol. (2017) 101:50717. doi: 10.1189/jlb.3A0116-028RR

41. Yoshida Y, Yoshimi R, Yoshii H, Kim D, Dey A, Xiong H, et al. The transcription factor IRF8 activates integrin-mediated TGF- $\beta$ signaling and promotes neuroinflammation. Immunity. (2014) 40:187-98. doi: 10.1016/j.immuni.2013.11.022

42. Ghoreschi K, Laurence A, Yang XP, Tato CM, McGeachy MJ, Konkel JE, et al. Generation of pathogenic $\mathrm{T}(\mathrm{H}) 17$ cells in the absence of TGF-beta signalling. Nature. (2010) 467:967-71. doi: 10.1038/nature09447

43. Ivanov, II, McKenzie BS, Zhou L, Tadokoro CE, Lepelley A, Lafaille JJ, et al. The orphan nuclear receptor RORgammat directs the differentiation program of proinflammatory IL-17+ T helper cells. Cell. (2006) 126:1121-33. doi: 10.1016/j.cell.2006.07.035

44. Mangan PR, Harrington LE, O'Quinn DB, Helms WS, Bullard DC, Elson CO, et al. Transforming growth factor-beta induces development of the $\mathrm{T}(\mathrm{H}) 17$ lineage. Nature. (2006) 441:231-4. doi: 10.1038/nature04754

45. Mufazalov IA, Schelmbauer C, Regen T, Kuschmann J, Wanke F, Gabriel LA, et al. IL-1 signaling is critical for expansion but not generation of autoreactive GM-CSF+ Th17 cells. EMBO J. (2017) 36:102-15. doi: $10.15252 / \mathrm{embj} .201694615$

46. Blum JS, Wearsch PA, Cresswell P. Pathways of antigen processing. Annu Rev Immunol. (2013) 31:443-73. doi: 10.1146/annurev-immunol-032712-095910

47. Becher B, Spath S, Goverman J. Cytokine networks in neuroinflammation. Nat Rev Immunol. (2017) 17:49-59. doi: 10.1038/nri.2016.123
48. Deng X, Sriram S. Role of microglia in multiple sclerosis. Curr Neurol Neurosci Rep. (2005) 5:239-44. doi: 10.1007/s11910-0050052-x

49. Luo C, Jian C, Liao Y, Huang Q, Wu Y, Liu X, et al. The role of microglia in multiple sclerosis. Neuropsychiatr Dis Treat. (2017) 13:1661-7. doi: 10.2147/NDT.S140634

50. Rutz S, Wang X, Ouyang W. The IL-20 subfamily of cytokines-from host defence to tissue homeostasis. Nat Rev Immunol. (2014) 14:783-95. doi: $10.1038 /$ nri3766

51. Bech R, Jalilian B, Agger R, Iversen L, Erlandsen M, Otkjaer $\mathrm{K}$, et al. Interleukin 20 regulates dendritic cell migration and expression of co-stimulatory molecules. Mol Cell Ther. (2016) 4:1. doi: 10.1186/s40591-016-0046-x

52. Dash R, Bhutia SK, Azab B, Su ZZ, Quinn BA, Kegelmen TP, et al. mda-7/IL-24: a unique member of the IL-10 gene family promoting cancer-targeted toxicity. Cytokine Growth Factor Rev. (2010) 21:381-91. doi: 10.1016/j.cytogfr.2010.08.004

53. Uto-Konomi A, Miyauchi K, Ozaki N, Motomura Y, Suzuki Y, Yoshimura A, et al. Dysregulation of suppressor of cytokine signaling 3 in keratinocytes causes skin inflammation mediated by interleukin-20 receptor-related cytokines. PLoS ONE. (2012) 7:e40343. doi: 10.1371/journal.pone.0040343

54. Qin H, Yeh WI, De Sarno P, Holdbrooks AT, Liu Y, Muldowney MT, et al. Signal transducer and activator of transcription-3/suppressor of cytokine signaling-3 (STAT3/SOCS3) axis in myeloid cells regulates neuroinflammation. Proc Natl Acad Sci USA. (2012) 109:5004-9. doi: $10.1073 /$ pnas. 1117218109

55. Lu HC, Kim S, Steelman AJ, Tracy K, Zhou B, Michaud D, et al. STAT3 signaling in myeloid cells promotes pathogenic myelin-specific $\mathrm{T}$ cell differentiation and autoimmune demyelination. Proc Natl Acad Sci USA. (2020) 117:5430-41. doi: 10.1073/pnas.1913997117

56. Okada $S$, Nakamura $M$, Katoh $H$, Miyao $T$, Shimazaki $T$, Ishii $K$, et al. Conditional ablation of Stat3 or Socs3 discloses a dual role for reactive astrocytes after spinal cord injury. Nat Med. (2006) 12:829-34. doi: $10.1038 / \mathrm{nm} 1425$

57. Emery B, Cate HS, Marriott M, Merson T, Binder MD, Snell C, et al. Suppressor of cytokine signaling 3 limits protection of leukemia inhibitory factor receptor signaling against central demyelination. Proc Natl Acad Sci USA. (2006) 103:7859-64. doi: 10.1073/pnas.0602574103

58. Liu Y, Gibson SA, Benveniste EN, Qin H. Opportunities for translation from the bench: therapeutic intervention of the JAK/STAT pathway in neuroinflammatory diseases. Crit Rev Immunol. (2015) 35:505-27. doi: 10.1615/CritRevImmunol.2016015517

59. Schwartz DM, Kanno Y, Villarino A, Ward M, Gadina M, O'Shea JJ. JAK inhibition as a therapeutic strategy for immune and inflammatory diseases. Nat Rev Drug Discov. (2017) 16:843-62. doi: 10.1038/nrd.2017.267

60. Horiuchi H, Parajuli B, Komiya H, Ogawa Y, Jin S, Takahashi K, et al. Interleukin-19 alleviates experimental autoimmune encephalomyelitis by attenuating antigen-presenting cell activation. bioRxiv. (2020). 2020.07.15.204826. doi: 10.1101/2020.07.15.204826

Conflict of Interest: The authors declare that the research was conducted in the absence of any commercial or financial relationships that could be construed as a potential conflict of interest.

Copyright (c) 2021 Horiuchi, Parajuli, Komiya, Ogawa, Jin, Takahashi, Azuma, Tanaka, Suzumura and Takeuchi. This is an open-access article distributed under the terms of the Creative Commons Attribution License (CC BY). The use, distribution or reproduction in other forums is permitted, provided the original author $(s)$ and the copyright owner(s) are credited and that the original publication in this journal is cited, in accordance with accepted academic practice. No use, distribution or reproduction is permitted which does not comply with these terms. 